\title{
Aníbal Quijano y la colonialidad del poder: todo lo sólido se desvanece en el aire
}

Andrea Barriga*

Si se define el ámbito de la ciencia por su capacidad de producir conocimientos que descubran las relaciones necesarias de los fenómenos, ello no lleva a identificar necesidad histórica (ex post facto) con inevitabilidad histórica (ex ante).

Carlos Pereyra, El sujeto de la historia, 1984.

A nuestro futuro lo definen incontables decisiones, cada decisión, cada momento, es una pequeña onda en el río del tiempo... Con suficientes ondas puedes cambiar la marea. Pues el futuro nunca está definido.

Charles Xaver, X-Men. Días del futuro pasado.

\section{Un primer acercamiento}

En las últimas décadas ha comenzado a consolidarse en América ("Latina" y "Anglosajona", para usar estos términos convencionales aunque algo engañosos) una corriente de pensamiento que se autodenomina "giro decolonial" o, como se ha propuesto recientemente, "descolonial". Su eje analítico lo constituye el "capitalismo colonial/moderno y eurocentrado" al que considera un nuevo patrón de poder mundial instaurado a partir del siglo XVI. Esta corriente se ha ido fortaleciendo no sólo en los ámbitos universitarios, sino que además su propuesta ha ingresado en diferentes áreas de formación profesional docente, como los diseños curriculares de las escuelas de educación primaria, media y terciaria, al menos, en Argentina. La "pedagogía decolonial" se ha ido introduciendo en algunos espacios educativos en los últimos años y está adquiriendo cierta relevancia: en muchos distritos ha pasado a ser, de hecho, prácticamente la visión oficial. También hay un aumento del arraigo de la propuesta decolonial en disímiles especialidades académicas. Se hace imprescindible, pues, un análisis de sus principales planteos teóricos o, como ellos los denominan, epistémicos.

* Instituto de Formación Docente Continua "Luis Beltrán", Río Negro, Argentina. https://orcid.org/0000-0001-5922-3354.
Mi acercamiento personal a esa corriente de pensamiento comenzó hace varios años, cuando finalizaba mis estudios de grado (el Profesorado en Historia) en la Universidad Nacional del Comahue, situada en las provincias argentinas de Río Negro y Neuquén. Estaba en la búsqueda de una teoría crítica que no fuera, o al menos no estuviera centrada, la teoría marxista. Esta búsqueda se fundamentó en lo que en su momento denominé un "empacho de marxismo". Este sentimiento tenía que ver con dos cuestiones que iban necesariamente de la mano. En primer lugar, la mayor parte de la bibliografía de la carrera, tanto en las materias de tilde más empírico como en las teóricas, pertenecía a esta corriente de pensamiento y necesitaba salir un poco de la "jaula del marxismo". Entiéndase: salir de las determinaciones económicas que pretendían dar una explicación del total funcionamiento de la sociedad. Este énfasis puesto en las estructuras económicas que determinan la superestructura no me satisfacía, porque creía que se dejaba fuera del análisis diferentes esferas que, a mi entender, eran importantes. Además, desde el comienzo de mis estudios había participado en importantes conflictos políticos que atravesaron a esa universidad, los más fuertes centrados en el rechazo a las reformas educativas neoliberales -iniciadas durante los '90- cuyo eje principal tendía a la mercantilización de la educación. Los grupos políticos predominantes en la facultad eran de tendencia marxista, la mayor parte de extracción trotskista y de forma minoritaria maoísta. Otras tradiciones 
políticas de gran importancia en la Argentina, como el peronismo, tenían escasa presencia en el movimiento estudiantil. Participé como estudiante en una agrupación independiente que, sin ser trotskista, era fuertemente marxista. Entre tanto, los debates, con ciertos grupos -a mi entender entonces- ultraradicalizados de tendencia trotskista, acerca de cómo llevar el conflicto adelante habían ayudado al rechazo que comencé a tener en relación a todo lo que tuviera que ver con el marxismo. Llevé todo a una simplificación tal que me indujo a mezclar prácticas políticas y teorías explicativas, ideales políticos y marcos conceptuales, capacidad explicativa y posibilidad de incidencia. Como si todo fuera lo mismo o fácilmente deducible una cosa de la otra; como si fuera una sola cosa, pasible de rechazo absoluto o asunción plena.

Fue en este momento de reconstrucción político-intelectual, de búsqueda de algo distinto pero crítico, que di con el pensamiento decolonial. El grupo estaba conformándose en la Universidad Nacional del Comahue. Cuando me acerqué, sus planteamientos me deslumbraron. Me parecieron innovadores, con una retórica que salía del "burdo lenguaje economicista del marxismo" (como lo consideraba en ese momento) y sentía que a partir de los aportes de esta corriente se abría un nuevo abanico de posturas críticas que abarcaban otras esferas de lo social, como la cultura, el lenguaje, la forma de enunciación e incluso la epistemología en la cual había sido formada. La retórica de la deconstrucción caló fuertemente en una mente inquieta que, una vez terminados los estudios de grado, necesitaba seguir explorando diferentes áreas del conocimiento y "otras" prácticas políticas de resistencia. Las críticas decoloniales al eurocentrismo, la modernidad y el marxismo me parecieron totalmente seductoras (y posteriormente enceguecedoras). Creía haber hallado la razón de todos los males: estamos colonizados.

Las generalizaciones decoloniales respecto a lo que se comprendía como modernidad me parecieron, en aquel momento, indiscutibles: la preponderancia de la racionalidad como forma de imposición del paradigma cuantitativo, surgido a partir de la filosofía cartesiana al servicio del capitalismo opresor; la unidireccionalidad del desarrollo del proceso histórico que mantenía la visión teleológica de la Edad Media; y la crítica a la civilización y la razón occidentales porque no lograban concebir al otro, sólo negarlo y dominarlo. En suma, la idea de una reconstrucción desde un paradigma "otro", que tuviera en cuenta saberes no considerados como válidos dentro del pensamiento hegemónico moderno, fue como un oasis en un desierto, una retórica completamente seductora. Por entonces suponía que todas estas problemáticas estaban rigurosamente estudiadas y que las audaces conclusiones estaban consistentemente argumentadas por los pensadores decoloniales que pretendían rechazar la totalidad de pensamientos desarrollados durante, al menos, cinco siglos.
No obstante, lo que en un principio se me había presentado como un conjunto político-intelectual de tilde crítico comenzó a incomodarme y empecé a sentir un desequilibrio. Al principio fue algo más vivencial que intelectual. Yo venía acostumbrada a una fuerte participación política en diferentes ámbitos y problemáticas, y lo que me ofrecía el grupo decolonial formado en la Universidad Nacional de Comahue era un espacio intelectual (restringido además a lo académico) pero nada de discusión ni participación en las problemáticas políticas generales del momento o particulares sobre la institución a la que pertenecíamos. Al contrario, las reuniones a las que asistí estaban centradas en cuestiones estrechamente académicas, como la escritura de artículos para su publicación y el armado de congresos del grupo de investigación que recibe el nombre de Centro de Estudios y Actualización en Pensamiento Político, Decolonialidad e Interculturalidad (CEAPEDI). El nombre era prometedor respecto a mis expectativas, no obstante las prácticas quedaban ceñidas a discusiones más bien teóricas y no siempre versaban sobre el "pensamiento político". En ese momento pensé que era una cuestión de tiempo, que no era fácil romper con ciertas prácticas cristalizadas en las instituciones incluso para quienes ya han roto intelectualmente con ciertos "marcos". Como fuera, no dejaba de incomodarme que los decoloniales del Comahue, al igual que el grueso de los grupos de investigación más convencionales, carecieran casi por completo de contacto con la práctica política. Éste, de hecho, ha sido uno de los motivos por los cuales había tomado otras elecciones en mi formación profesional. No porque esta forma de concebir el conocimiento "estuviera mal": simplemente porque, en lo personal, elegía otros espacios de debate y participación política que no estaban -ni están- en los ámbitos académicos.

Luego de acompañar a este grupo por un tiempo, desde un lugar secundario (o marginal), me di cuenta que su dinámica no tenía ninguna diferencia con las de cualquier otro grupo de investigación de la universidad. La diferencia era temática. Lo que en un primer momento había vislumbrado como una alternativa teórica y de práctica política no compensaba la parte de praxis política de mis expectativas. En consecuencia, comencé a alejarme del mismo para dedicarme de lleno a comprender el desarrollo intelectual, intentando no juzgar por la ausencia de estas prácticas al contenido teórico de la opción decolonial. Mis inquietudes políticas las continué por fuera del ámbito académico y me dediqué a profundizar el estudio de sus postulados epistémicos y a investigar con qué teorías y pensadores se estaba discutiendo.

\section{Continuación del desencanto}

Luego de recibirme comencé mi desempeño laboral, primero en 
instituciones de Educación Media y luego en una de Educación Terciaria. La investigación comenzaba a correr por cuenta personal ya que desde estas instituciones no hay financiamiento para ello, como sí lo hay en las universidades. Esto, que puede ser visto como una desventaja material, me permitía mucha libertad para profundizar mis estudios sin la necesidad de cumplir con requisitos o plazos institucionales. Decidí profundizar en el pensamiento decolonial $y$, aprovechando que debía ahondar en los temas de los espacios curriculares que dictaba (y dicto en la actualidad: Antropología, Filosofía, Economía y Teoría de la Historia), analicé a partir de allí esa "episteme moderna y eurocentrada" con la que discuten y a la que critican. Me pareció una oportunidad realmente enriquecedora para desarrollar aún más la crítica y poder "desprenderme" del entramado epistémico eurocentrado aprendido en la formación de grado.

Para comenzar la sistematización de mis estudios decoloniales me centré, en un principio, en uno de los ejes que se presentan como fundamentales: la modernidad. La idea era contrastar lo que los decoloniales planteaban como modernidad con los pensamientos eurocéntricos que justamente la constituían. Mi lectura había sido hasta el momento desordenada. Comencé a sistematizarla con uno de los pensadores decoloniales más reconocido que justamente se encarga del tema elegido: Walter Mignolo. Paradójicamente, mientras más avanzaba en la lectura de sus escritos, tenía una idea más confusa de lo que denominaba "modernidad". Parecía ser que "moderno" era todo aquello pensado en, o influenciado por, lo que se pensaba en Europa. Junto a ello tampoco encontraba un recorte histórico coherente. En cada escrito de Mignolo me encontraba con un recorte temporal distinto y no quedaba nunca clara la justificación del mismo. No obstante, aunque cuanto más leía menos me convencían los argumentos de Mignolo, sus apelaciones al "desprendimiento" y su llamado a combatir el eurocentrismo y las lenguas coloniales continuaban tocando una fibra íntima.

La perspectiva decolonial me ayudaba a dar sustento a algunas posturas políticas que siempre me había costado sostener en el ámbito intelectual, por ejemplo mi negación a profundizar el conocimiento del inglés. Esto lo podía justificar ahora teniendo en cuenta que:

sería equívoco asumir que los legados teóricos de las lenguas de la modernidad (francés, alemán, inglés) son los únicos con legitimidad científica. Inscribir las lenguas del primer periodo colonial (español, portugués, quechua, aymara, náhuatl) en las lenguas teóricas de la modernidad es un primer paso hacia la descolonización intelectual y hacia la negación de la negación de la contemporaneidad [destacado en original].

1 Walter Mignolo, "El lado más oscuro del Renacimiento", en Universitas humanística n. ${ }^{\circ} 67,2009$, pp. 168-169.
La opción decolonial me permitía justificar mi preferencia por aprender mapuzugun y mi negación al inglés. Aprender mapudugun me acercaba a la cosmovisión mapuche y me ayudaba a "descolonizar mi ser". Y la opción decolonial parecía reivindicar mi carácter "situado".

El territorio que habito sólo lleva algo más de cien años en manos del Estado, tanto argentino como chileno. Recién a fines del siglo XVIII, 1880 para ser precisa, los estado-nación avanzaron con violencia sobre las comunidades indígenas, a las cuales pertenecía este territorio. En el caso del estado argentino bajo el lema "conquista del desierto", y en el del estado chileno, "pacificación de la Araucanía", las campañas militares cometieron asesinatos despiadados, separaron comunidades y se llevaron a las mujeres y niños para ser vendidos en Buenos Aires como empleadas/os domésticos y a los hombres para trabajar en el Norte bajo el régimen seudoesclavista de los ingenios azucareros. ${ }^{2} \mathrm{~A}$ quienes se resistían se los mataba. Gracias a la tenacidad de estos pueblos, algunas comunidades han logrado sobrevivir, aunque siempre amedrentadas por el Estado. Les siguen sacando las tierras por la fuerza para vendérselas a Benetton y Lewis, para hacer "parques nacionales" o para expandir las ciudades. ${ }^{3}$ Las heridas aquí son recientes. Nietos y bisnietos de quienes se enfrentaron con las fuerzas del Estado son hoy adultos. Una batalla fuerte se mantiene además en los ámbitos político y académico. La cultura impuesta por los estados nacionales ha sembrado la idea de que estas tierras eran parte del imperio hispano. Que también en esta parte del mundo el colonialismo lleva quinientos años, una mentira que se instala hondamente en el "sentido común" de la población y que lleva a negar la identidad del pueblo mapuche.

La historia del territorio hoy conocido como Patagonia no es indiferente a mi reconstrucción identitaria y creí que la propuesta decolonial me permitiría darle un nuevo giro a esa búsqueda. Pero en ese momento personal e intelectual, releyendo más

2 Hace muy poco tiempo que se comenzaron a cuestionar en Argentina las miradas historiográficas respecto a los pueblos originarios, ya que la historia tradicional los trata como si estuviesen muertos. De esta visión, el más representativo es Rodolfo Casamiquela, que ha profanado cementerios mapuche para "reconstruir el pasado de las comunidades indígenas", cuando sus familiares, nietos, bisnietos, aún están con vida. Un excelente trabajo historiográfico, que clarifica la cuestión y saca a relucir las hipocresías de los discursos predominantes, lo ha llevado a cabo, junto a intelectuales comprometidos como Walter Delrío, Diana Lenton, entre otros, nuestro queridísimo Osvaldo Bayer, Intelectual y militante, que ha acompañado durante casi toda su vida la lucha de los pueblos originarios, incluso cuando era una voz disonante, antes de que este tema fuera "moda" para los intelectuales.

3 Un ejemplo de la violencia de la que siguen siendo víctimas por parte del estado argentino estas comunidades se encuentra en el caso de desaparición y posterior muerte de Santiago Maldonado en 2017 en manos de la gendarmería y de Rafael Nahuel acribillado por la espalda por la prefectura naval argentina el mismo año. Ambos participaban de los movimientos de recuperación de tierras llevados adelante por algunas comunidades. En el caso chileno, a finales del 2018 la muerte de Camilo Catrillanca, luego de un allanamiento a cargo del Comando Jungla de Carabineros en la comunidad de Ercilla, es otra muestra de la violencia despiadada de ambos estados. 
detenidamente El lado más oscuro del Renacimiento, me encontré con el siguiente comentario del autor, que me permito citar en extenso:

Entonces, ¿por qué escribir este texto originalmente en inglés y no en español? En este momento, escribir en español significa quedar al margen de las discusiones teóricas contemporáneas. En el mundo donde las publicaciones académicas son significativas, hay más lectores en inglés y francés que en español. Como los estudiantes cuando escriben una disertación en estudios literarios, esto requiere un doble esfuerzo: conocer el canon y el corpus. Escribir en español un intento por inscribir los legados hispanos y latinoamericanos e indígenas en los actuales debates sobre el Renacimiento/ periodo moderno temprano y en los legados coloniales y teorías poscoloniales significa marginalidad antes que tener la posibilidad de participar en una conversación intelectual que, desde el siglo XVIII, ha estado dominada por el alemán, el francés $y$, más recientemente, por el inglés [destacado $A B$ ]. ${ }^{4}$

En su momento me quedé sin forma de enunciar mi sentimiento al respecto. No sabía si me indignaba más o la hipocresía de hablar de descolonización -haciendo énfasis justamente en las lenguas coloniales- y al mismo tiempo escribir ( $y$ justificar esa escritura) en la lengua que actualmente es la colonizadora por excelencia, heredera cultural de lo que Mignolo mismo denomina eurocentrismo; o la justificación de la escritura en inglés para no quedar al "margen de los debates". Me pregunté (y aún me lo pregunto): ¿con quién quiere debatir Walter Mignolo? ¿Hay realmente una genuina búsqueda por mostrar a los "dominados", a los "colonizados", cómo es que pasamos a formar parte de esta colonización? ¿O, más bien, se trata de un intento de buscar "reconocimiento" dentro de una élite intelectual cuya forma de diálogo obliga a renunciar a la lengua madre del autor y a hacer un esfuerzo de escribir en una lengua cuya única justificación es ser la lengua de los poderosos? ¿Hay un verdadero planteamiento crítico o es la conformación de otra "élite intelectual" dentro de los ámbitos académicos que busca el reconocimiento de los que ya están instalados? Es cierto que la lengua más hablada en América Latina es el español, la lengua de los colonizadores, diría Mignolo, pero ¿es el inglés -la lengua impuesta por la potencia hegemónica mundial que lejos está de romper con la "colonización del ser, y mucho menos del saber"la adecuada para descolonizarnos?

Con todos estos interrogantes, y la indignación que los acompañaba, decidí no dar por tierra con lo que se presentaba como una corriente alternativa de pensamiento por uno de sus autores (aunque, recordemos, uno de los fundamentales). No quería sentirme nuevamente "despojada" de lo que creía había encontrado como salida a mis inquietudes aunque éstas, en

$4 \quad$ Walter Mignolo, op. cit., p. 168. vez de irse diseminando, iban mutando de forma. Ya me había decepcionado la falta de interés en la praxis política del CEAPEDI, ahora me encontraba con afirmaciones difíciles de tragar por parte de Mignolo. ¿Qué más me podía encontrar? Decidí explorar. Nuevamente, el análisis de otro de los autores que, según los propios decoloniales, más representa y ha desarrollado esta línea de pensamiento y, a mi entender de ese momento, uno de los más sólidos exponentes. Se trata, de hecho, de quien acuña el concepto de colonialidad: Aníbal Quijano.

\section{¿Quién es Aníbal Quijano?}

Los textos sobre colonialidad del autor ya los había leído. Pero continuaba en mi afán de ser sistemática para comprender mejor sus planteamientos. Al mismo tiempo, pretendía contrastarlos con otras lecturas, tal como había sido mi proyecto con Mignolo. En los artículos que conocía de Quijano siempre había uno u otro concepto o afirmación que no estaba desarrollado. El autor aclaraba usualmente que eso se debía a la falta de espacio y remitía a otro artículo escrito por él en el que supuestamente estaba mejor trabajado el tema. Por lo tanto, para leerlo de la forma que me proponía debía hacer un rastreo minucioso de su bibliografía.

La misma es extensa: Quijano comienza sus escritos en la década de los cincuenta del pasado siglo y tiene una producción constante hasta poco antes de su fallecimiento. En sus aproximadamente dos centenares de publicaciones (sumando entrevistas, conferencias, artículos y cinco libros), discute variados temas, todos los cuales están en consonancia con las discusiones predominantes en los ámbitos académicos. Casi un cuarto de sus escritos está publicado fuera de América Latina: en Estados Unidos, Italia, Alemania y Polonia, entre otros países. Desde fines de 1950 y principios de los sesenta, sus preocupaciones mayoritariamente se abocan a los conflictos culturales en Perú, específicamente a la "emergencia del grupo Cholo", a los movimientos campesinos, a los procesos de urbanización y a la marginalidad social de ellos derivados. ${ }^{5}$ Quijano realizó varios de estos últimos estudios durante su colaboración con la División de Asuntos Internacionales de la CEPAL. Hacia fines de los sesenta,

5 Aníbal Quijano, "La Emergencia del Grupo Cholo en el Perú", en Memorias del VII Congreso Latinoamericano de Sociología, Bogotá, 1964; "El movimiento campesino peruano y sus líderes", en América Latina $n^{\circ}$ 4, Río de Janeiro, 1965; «Los movimientos campesinos contemporáneos de América Latina», en Seymor Martín Lipset y Aldo Solari (eds.), Las Elites Contemporáneas De América Latina, Buenos Aires, Paidós, 1966; "I Movimenti Contadini Contemporanei", en Rivista Di Economía Agraria, Vol. 5, n² 21, 1966; Notas sobre el concepto de "marginalidad social", Santiago de Chile, División de Asuntos Sociales, CEPAL, 1966; El proceso de urbanización en América Latina, Santiago de Chile, División de Asuntos Sociales, CEPAL, 1966; La urbanización de la sociedad en América Latina, Santiago de Chile, División de Asuntos Sociales, CEPAL, 1967. 
se incrementó su preocupación por las discusiones sobre la Teoría de la dependencia, ${ }^{6}$ y entrada la década del setenta, comenzó a sumergirse en los debates respecto al imperialismo, el neoimperialismo y la crisis del mismo, ${ }^{7}$ la dominación cultural y lucha de clases, temas que abarcan con diferentes énfasis toda la década. ${ }^{8}$ A partir de los años ochenta, suma nuevas problemáticas, como el debate sobre lo público y lo privado, la democracia, la tecnología y el desarrollo. ${ }^{9}$ En la década siguiente comenzarán a tomar mayor entidad en el pensamiento de Quijano las discusiones respecto a las crisis de las ciencias sociales y el socialismo real, como así también los debates respecto a la modernidad/posmodernidad. Será ése el momento en el cual comenzará a configurar su pensamiento decolonial, ${ }^{10}$ sin pasar por alto los debates que se daban entonces respecto al Estado, la nacionalidad y la globalización. "Y Ya en el 2000, tomará gran centralidad dentro de las elaboraciones teóricas del autor la colonialidad del poder. Como podemos observar, ha "estado al pie del cañón" para discutir temáticas diversas, que afloraban en los ámbitos intelectuales y políticos de cada momento histórico. Aquí me abocaré a indagar cómo Quijano primero va sugiriendo o insinuando, y luego termina consolidando, la conceptualización de la "colonialidad del poder".

6 A. Quijano, "Urbanización, Cambio Social y Dependencia", en Fernando Henrique Cardoso y Francisco Weffort (eds.), América Latina. Ensayos de Interpretación Sociológica, Santiago de Chile, Editorial Universitaria, 1967; Urbanización y tendencias de cambio rural en América Latina, Santiago Chile, División de Asuntos Sociales, CEPAL, 1967.

7 A. Quijano, Nacionalismo, Neoimperialismo y Militarismo en el Perú, Buenos Aires, Periferia, 1971; Nationalism and Capitalism in Peru, Nueva York y Londres, Monthly Review Press, 1971; Crisis Imperialista y Clase Obrera en América Latina, Lima, Fondo Editorial Popular, 1974; "La naturaleza de la crisis actual del capitalismo", en Economía n 62, Quito, diciembre de 1975 .

8 A. Quijano, Imperialismo, clases sociales y Estado en el Perú 18951930, Mosca Azul, Lima, 1979. Este libro despierta un interesante debate: Augusta Alageme, "Imperialismo y problema Nacional: a propósito de algunas tesis de Aníbal Quijano", en Revista de la Universidad Católica $n^{\circ} 5,15 / 08 / 1979$

9 A. Quijano, "Los usos de la democracia burguesa", en Sociedad y Política $n^{\circ} 10$, Lima, noviembre de 1980; "Poder y democracia en el socialismo", en Sociedad y Política n 12, agosto de 1981; "Über die direkte demokratie der Produzenten", en Lateinamerika $n^{\circ} 5$, Berlín, 1981; "Tecnología del transporte y desarrollo urbano", en Aproximación Crítica a la Tecnología en el Perú, Lima, Mosca Azul, 1982; "Lo público y lo privado: un enfoque latinoamericano", en Modernidad, Identidad y Utopía en América Latina, Lima, Sociedad y Política Ediciones, 1988.

10 "Notas sobre la crisis de las ciencias sociales", en Revista de Sociología, vol. 6. № 7, Lima, 1990; "La crisis en Europa del Este y la Izquierda en América Latina", en Cultura Libre. Suplemento de Pagina Libre, Lima, 29/08/1990; "La Modernidad, el Capital y América Latina", en Revista del Centro de Educación y Cultura ILLa n 10, enero de 1991; "Colonialidad y modernidad/racionalidad", en Perú Indígena, Vol. 13, n. ${ }^{\circ} 29,1991$, pp. 11-20; "Reflexions sur LInterdisciplinarite, le Developpement et les Relations Interculturelles", en Entre Savoirs, París, 1992; "Colonialité du Pouvoir et Democratie en Amerique Latine", en Future Anterieur: Amérique Latine, Democratie Et Exclusion, París, L`Harmattan, 1994, y en castellano, en Debate, Vol. XVI, n. ${ }^{\circ}$ 77, marzo-mayo 1994.

11 A. Quijano, "Estado-nación, Ciudadanía y Democracia. Cuestiones abiertas", en Helena Gonzáles y Heidulf Schmidt (comps.), Democracia para una Nueva Sociedad, Caracas, Nueva Sociedad, 1997; «Globalización y exclusión desde el futuro", en La República, Lima, 24/08/1997.

\section{Un tropezón no es caída}

Al discutir la obra de Aníbal Quijano uno de los primeros problemas con el que nos encontramos es que no podemos encasillarla dentro de una disciplina específica más allá de que el autor se reconoce como sociólogo. En un principio, cuando comencé a sumergirme en ella hace algunos años, me pareció una virtud haber logrado romper con lógicas disciplinares que tanto mal han hecho a las ciencias sociales. Inmediatamente, se me vino a la cabeza la idea de Immanuel Wallerstein (quizá porque Quijano había escrito algunos artículos con este intelectual) de ese "nuevo constructo disciplinar" que denominaba "ciencias sociales históricas". Decía Wallerstein para justificar su propuesta:

No es posible referirse al mundo real con enunciados que no estén relacionados con la ciencia; con esto me refiero al supuesto de que el mundo es real y puede conocerse. Cada una de las palabras que usamos cuando hablamos o escribimos lleva detrás una teoría y un gran relato, y no hay forma de escapar a eso, por mucho que lo intentemos. Por otro lado, el mundo no puede analizarse y describirse sin situarse en la historia, y con esto quiero decir que toda realidad forma parte de un contexto que cambia y evoluciona continuamente. $^{12}$

Sin embargo, a medida que iba profundizando mi lectura, me daba cuenta de que esto en la producción de Quijano era un gran problema. En sus escritos se juntaban grandes generalizaciones, falta de datos empíricos para sostener afirmaciones al menos discutibles -cuando no errores empíricos de gran peso- y una mezcla de niveles o campos filosófico, científico y político, que deriva en una gran dificultad para comprender lo que Quijano plantea o en qué sentido lo plantea. Sin embargo, no me di por vencida. Fui intentando ordenar la discusión para comprender qué discutía, con qué teoría o autores estaba discutiendo, en fin, intenté aclarar y precisar los conceptos y argumentos que se desarrollaban a lo largo de su obra.

Uno de los primeros textos que leí del autor para ordenar la génesis del concepto de colonialidad fue "Colonialidad del poder y clasificación social", publicado por primera vez en 2000 (en inglés, en 2007 en español). El texto comienza afirmando que la colonialidad junto a la modernidad son los elementos constitutivos del capitalismo (que denomina patrón mundial de poder) y que se fundan a partir de la constitución de América Latina y la imposición de la clasificación racial del mundo. Visto así pareciera indiscutible. Pero el concepto de modernidad reaparecía, como en la obra de Mignolo, como central y el

12 Immanuel Wallerstein, Las incertidumbres del saber, Barcelona, Gedisa, 2005 , p. 24 
autor no desarrollaba el mismo, sino que remitía a escritos anteriores en los cuales habría discutido el tema. Pero antes de rastrear estos escritos, me encontré nuevamente con algo que comenzó a desalentarme bastante, no en cuanto a la discusión epistémica, si se quiere, sino más bien respecto a un "desliz" histórico absolutamente impropio de un crítico del colonialismo y la colonialidad. Se trata de una cita al pie en la segunda página de este texto en la que se refiere a "la constitución de América Latina [sic]", la cual transcribo en su totalidad:

La apropiación del nombre "América" por Estados Unidos ha originado una extendida confusión que aquí nos obliga a recordar que originalmente el nombre correspondía exclusivamente a los dominios ibéricos en este continente, que abarcaban desde Tierra del Fuego hasta más o menos la mitad suroeste del actual territorio de los Estados Unidos [destacado $A B]^{13}$

Como tuve la oportunidad de comentar más arriba, esto no sólo es históricamente falso, sino que es políticamente inaceptable, en especial dentro de un texto que plantea la imposición de la colonización racial como eje constitutivo del actual patrón de poder.

Comenzaba así a fortalecer mi desencanto. Aunque, a pesar de ello, no descarté al autor y su planteamiento. Volvía, empero, a sentir esa indignación que tuve con algunos marxistas que hablaban del obrero y nunca habían sentido en su piel la explotación laboral, o hablaban de los pobres y habían crecido en Recoleta, ${ }^{14}$ ya que iba sumando cuestiones que me hacían percibir, más que un convencimiento epistémico, una pose académica. Fue en este momento que hice un primer cambio en mi forma de pensar. Comprendí que no podía juzgar una teoría por los usos que se hicieran de ella: una cosa es la teoría en tanto búsqueda de explicar, comprender o describir el devenir de las sociedades y otra cosa muy distinta son las interpretaciones y los usos que se hacen de ellas ${ }^{15}$. Con esto en mente, decidí centrarme en las propuestas teóricas de Quijano, pero también de otras corrientes explicativas que había desechado, como lo era el marxismo. Esta vez me iba a centrar sólo en las discusiones teórico-epistémicas de los diferentes campos del saber teniendo como eje lo rescatable de cada propuesta y Quijano seguía, en este sentido, pareciéndome lo más sólido dentro del campo

13 A. Quijano, "Colonialidad del poder y clasificación social", en Cuestiones y horizontes: de la dependencia histórico-estructural a la colonialidad/ descolonialidad del poder, Buenos Aires, Clacso, 2014, p. 286, cita al pie $n^{\circ} 2$.

14 Recoleta es uno de los barrios de Buenos Aires en que vive una población con gran poder adquisitivo, parte de la clase media alta de la sociedad argentina.

15 Aunque debo decir que en los casos de Quijano y Mignolo no se trataba de usos que otros hacían de sus teorías, como se puede ver en el caso del marxismo, sino que los mismos autores, en el desarrollo de su teoría, tropezaban con contradicciones importantes. decolonial.

\section{La colonialidad... ¿una nueva forma de universalismo?}

El concepto de colonialidad fue acuñado por Quijano y, como pasó a ser uno de los centrales, decidí iniciar allí mi análisis. Según el autor, la colonialidad hace referencia a una episteme eurocentrada que se conforma a partir del ingreso de América al sistema mundo capitalista y que se constituye a partir de la clasificación étnico/racial de las sociedades. Todo lo que conformaría el pensamiento racional moderno. A rasgos generales, parecía completamente aceptable, pero me interesaba saber qué significaba aquello, cómo estaba sustentado y cuáles eran los argumentos que se esgrimían para su defensa, ya que como una "nueva teoría", debía tenerlos.

Concebía que lo novedoso del planteo residía: primero, en tener en cuenta la clasificación racial en el marco de la conformación de las relaciones de poder dentro de las sociedades actuales; segundo, en la afirmación de que la discriminación racial no se acaba con el fin del colonialismo económico y político, sino que se mantiene como colonialismo epistémico. Ambos planteos me parecían aceptables. Pero no me parecían novedosos. Idénticas tesis, o muy semejantes, había sido expuestas con anterioridad, aunque lamentablemente Quijano no daba cuenta de ello. Por ejemplo, Frantz Fanon ya en 1961 ponía en discusión la importancia de la racialidad respecto a la situación del colonialismo europeo en África. Posteriormente, Peter Worsley, en su obra más reconocida, El tercer mundo (1973), hacía un análisis muy interesante acerca de por qué el colonialismo europeo se diferenciaba de otros tipos de colonialismo que habían existido. En consideración al segundo punto, hay un debate riquísimo en antropología que data de la década del setenta del siglo pasado y la bibliografía al respecto es bastante voluminosa. Baste mencionar el sugestivo libro de Jack Goody La domesticación del pensamiento salvaje (1977). Allí leemos: "El problema con las categorías es que están enraizadas en una división nosotros/ ellos, que es a la vez binaria y etnocéntrica, cada uno de estos hechos es limitativo de un modo propio". Además recordemos las discusiones planteadas sobre este punto por Peter Winch en varias de sus obras. Por consiguiente, después de un poco de búsqueda -para nada exhaustiva-, lo novedoso parecía no serlo tanto. Desgraciadamente, Quijano nunca cita o hace referencia a estos debates o pensadores.

Seguí rastreando el concepto de colonialidad en Quijano a fin de no perderme detalles. Llegué así a un artículo escrito en 1991, titulado "Colonialidad y modernidad/racionalidad" que, según el mismo autor, es el texto en el que introduce este 
concepto. Me encontré que a lo largo de las diez páginas del escrito hace fuertes afirmaciones que continuará desarrollando en artículos posteriores. Es un texto muy comprimido en el cual no hay referencia bibliográfica y en el que busca discutir la total construcción filosófica y científica europea, desde el siglo $\mathrm{XV}$ hasta el siglo XX. En tan poco espacio, el autor no puede desarrollar en profundidad los temas que plantea quedando así la mayoría de las cosas como fuertes afirmaciones, sin suficiente sustento teórico o empírico.

Pero acaso lo más original de Quijano sea su énfasis en la constitución de lo europeo y no europeo a partir del descubrimiento de América. ${ }^{16}$ Este punto de partida le permitirá ir consolidando la idea de la importancia de América para explicar lo ocurrido en el mundo desde el siglo XV hasta la actualidad. Desde una perspectiva histórica, este hecho (la importancia de la conquista de América) es innegable. El problema se plantea en lo referente a la centralidad cuasi-única que le otorga. Esto es complejo, ya que sus escritos no pretenden ser sólo una reconstrucción o afirmación de identidad, sino que pretenden conformar las bases de una nueva episteme, es decir, un nuevo marco teórico desde el cual analizar y explicar los acontecimientos mundiales. Si el autor entiende por episteme alguna otra cosa, no lo ha dejado explícito.

No obstante, el peligro mayor radica (sea en el sentido de buscar una reconstrucción identitaria o de formular un nuevo marco teórico) en que lo que comienza siendo una crítica al etnocentrismo europeo -eurocentrismo, como le gusta denominarlo a Quijano- estaría lindando un etnocentrismo latinoamericano, americocentrismo. Como vamos a ir viendo, para Quijano todo nace con América. $Y$ esto es algo cuestionable desde un punto de vista histórico. Y también lo es desde un punto de vista político.

Pero veamos cómo se desliza esta idea. Quijano plantea que América fue la que más sufrió el colonialismo europeo, al punto tal que afirma:

América Latina es, sin duda, el caso extremo de la colonización cultural por Europa. [...] En el África, la destrucción cultural fue sin duda mucho más intensa que en el Asia; pero menor que en América. Los europeos no lograron tampoco allí la destrucción completa de los patrones expresivos, en particular de objetivación y formalización visual. Lo que

16 Es viable pensar, por el recorrido intelectual del autor, que la impronta en este punto esté dada porque al año siguiente, en 1992, se cumplían los 500 años de la "conquista de América" y toda la intelectualidad, no sólo americana sino mundial, tenía sus ojos puestos sobre el tema. Esto se podría reafirmar si consideramos que otro de los textos fundantes de la idea de colonialidad -según el mismo Quijano señala en más de una ocasión- es publicado en 1992: Aníbal Quijano e Immanuel Wallerstein, "La americanidad como concepto, o América en el moderno sistema mundial", en Revista Internacional de Ciencias Sociales n. ${ }^{\circ} 134$, diciembre de 1992, pp. 583-591. En este texto ya se puede ver una de las introducciones al tema de "la raza". hicieron fue despojarles de legitimidad y de reconocimiento en el orden cultural mundial dominado por los patrones europeos [destacado AB]. ${ }^{17}$

Aquí vemos como utiliza el mismo paradigma supuestamente eurocentrado que critica, y lo hace de modo un tanto abusivo. Primero porque intenta una cuantificación de procesos sociales complejos para los que no es nada evidente que podamos reducir todas las variables pertinentes a un denominador común. Segundo porque toma como totalidades a América y a África, que son precisamente construcciones hechas desde la mirada europea: los pueblos de "África" y de "América" sólo conformaban una unidad para los europeos, no para ellos mismos. Pero ¿cómo medir si los americanos son los más sufridos, los más despojados, los más colonizados? Y además, ¿son lo mismo los tehuelches que los mayas, los guaraníes que los quilmes? No pongo en duda el sufrimiento y despojo de los pueblos originarios: lo vivencio cotidianamente en un territorio en el que el Estado ha asesinado impunemente a Rafael Nahuel y a Camilo Catrillanca, por poner dos ejemplos recientes a uno y otro lado de la Cordillera de los Andes. Pero no nos olvidemos que el apartheid duró en Sudáfrica hasta 1994. Las comparaciones sólo sirven como medio analítico con algún fin específico. No sirven para comparar sufrimientos o para saber cuáles de los pueblos colonizados fueron más despojados cuando el despojo hace referencia a la parte inmaterial de la cultura. Quijano, pues, hace lo que critica: evalúa a partir de valores no reconocidos como tales, y ocultos tras una retórica de pretensión científica, pero que no especifica cómo podríamos cuantificar el sufrimiento. ¿Cómo medir si una destrucción cultural fue más o menos intensa, mayor o menor en un lugar que en otro? ¿Podría alguien pensar que el apartheid, como caso extremo de racismo sufrido por algunos pueblos africanos, no implicó una "destrucción completa de los patrones expresivos, de objetivación y formalización visual"?

\section{Racialidad: lo que pretende aclarar y lo que oculta}

Otro de los conceptos que va a tomar cada vez mayor importancia en la obra de Quijano es el de raza. Para el autor, el nacimiento de América, y en consecuencia de Europa, es central para comprender la colonialidad y la racialidad de ella derivada. Ejes de la conformación del nuevo patrón de poder mundial que surgiría en el siglo XV. En sus propias palabras: "En 1492, con el nacimiento de América y de Europa, del capitalismo y de la modernidad, se inicia un proceso de brutal y violenta reconcentración de los recursos del mundo".8 Más adelante

17 A. Quijano, "Colonialidad y modernidad/racionalidad", op. cit., p. 13.

18 A. Quijano, "América Latina en la economía mundial" (1993), en Cuestiones y horizontes. De la dependencia histórico-estructural a la colonialidad/descolonialidad del poder, Buenos Aires, Clacso, 2014, p. 
agrega:

lo que emergió como radicalmente nuevo en la conquista y destrucción de las sociedades precolombinas y la formación de América: la constitución de las categorías que ahora conocemos como "raza", "color", "etnia" y el derivado complejo "racismo/etnicismo", como elementos fundantes e inherentes a la relación de poder entre europeos y noeuropeos. ${ }^{19}$

Las afirmaciones contenidas en este párrafo no coinciden con lo que yo sabía -o creí saber - sobre el tema. El concepto de raza se puede rastrear en la llustración europea, situada históricamente en el siglo XVII, y más aún es el evolucionismo biologicista -que se consolida recién en el siglo XIX- el que toma esta categoría como central. Pensé en ese momento que quizá sería mi formación eurocentrada la que me hacía dudar del planteamiento de Quijano. Por lo tanto, me puse a rastrear cómo desarrollaba el autor la idea de raza. Cual caballo de ajedrez comencé a saltar de un texto a otro según el autor me iba indicando en cuáles había discutido el tema. Así encontré continuamente, en diferentes escritos, afirmaciones del estilo de "la idea de raza no existe en la historia del mundo antes de América", o:

La idea de raza es, con toda seguridad, el más eficaz instrumento de dominación social inventado en los últimos 500 años. Producida en el mero comienzo de la formación de América y del capitalismo, en el tránsito del siglo XV al $\mathrm{XVI}$, en las centurias siguientes fue impuesta sobre toda la población del planeta como parte de la dominación colonial de Europa. ${ }^{20}$

Al fin di con el texto -guiada por las citas del autor- en el cual desarrolla este planteamiento. Publicado en 1993, "Raza, etnia y nación en Mariátegui" es el ensayo en el cual a lo largo de sus casi veinte páginas, tocando variados temas, plantea el surgimiento de la idea de raza en 1492. Lo esencial del argumento se halla en la siguiente cita:

Con la formación de América se establece una categoría mental nueva, la idea de "raza". Desde el inicio de la conquista, los vencedores inician una discusión históricamente fundamental y sobre si los aborígenes de América tienen "alma" o no; en definitiva si tienen o no naturaleza humana. [...] Desde entonces, en las relaciones intersubjetivas y en las prácticas sociales del poder, quedó formada, de una parte, la idea de que los no-europeos tienen una estructura biológica

\section{5}

19 A. Quijano, op. cit., p. 206

20 A. Quijano, “iQué tal Raza!", en Ecuador debate n. ${ }^{\circ} 48$, diciembre de 1999, p 141. no solamente diferente de la de los europeos; sino, sobre todo, perteneciente a un tipo o a un nivel "inferior". De otra parte, la idea de que las diferencias culturales están asociadas a tales desigualdades biológicas y que no son, por lo tanto, producto de la historia de las relaciones entre las gentes y de éstas con el resto del universo. [...] Ese complejo es lo que conocemos como "racismo".27

Estas afirmaciones me llevaron a la búsqueda del sustento empírico de la tesis de Quijano. Hice una relectura de las fuentes que el mismo Quijano cita, como los escritos del Fray Bernardino de Sahagun o de Fray Bartolomé de las Casas. Eran textos que ya había leído y no tenía registro de que raza fuera un concepto incorporado en ellos. Y la relectura me lo confirmó. No existe en estos textos ni en otros de la época la mención del concepto de raza.

Pero busquemos un poco más en profundidad. Quijano muestra dos concepciones sobre lo que incluiría la raza, que son disímiles y que pertenecen a diferentes épocas históricas. La concepción biológica en la idea de raza es muy posterior a 1492. Es una idea conformada incipiente y marginalmente a partir de la Ilustración. Deberemos esperar hasta el siglo XIX para que sea una idea relativamente central dentro del desarrollo de las nacientes ciencias sociales. Dice Marvin Harris al respecto: "aunque la actividad intelectual del siglo XVIII se interesara profundamente por la evolución, el racismo científico siguió siendo hasta después de la Revolución francesa el punto de vista de una minoría". 22 Por consiguiente, pensé que quizá Quijano se refiriera a la idea de evolución sociocultural, sin justificación biológica, como forma de concepción nacida con la llegada de los europeos a América. Pero esto tampoco es sostenible: la idea está presente en el pensamiento occidental desde mucho antes del ingreso de América a la "episteme" europea. Podemos rastrear esta forma de concepción del devenir histórico hasta los griegos. Como expusiera Harris:

En realidad, en la cuestión de la evolución sociocultural la Ilustración se limitó a volver a colocar en una posición intelectualmente respetable una doctrina existente desde muy antiguo. Todo el pensamiento evolucionista de la Ilustración delata la influencia de Lucrecio, el gran poeta y filósofo materialista romano del siglo I d.C. En su poema De la naturaleza de las cosas, Lucrecio, que se inspiraba en otras ideas evolucionistas aún más antiguas, las expresadas por el griego Epicuro, alcanzó un nivel de comprensión de la evolución sociocultural y biológica que no sería igualado

21 A. Quijano, "〈Raza〉, 〈etnia〉 y 〈nación〉 en Mariátegui. Cuestiones abiertas", en Cuestiones y horizontes..., op. cit., p. 759.

22 Marvin Harris, El desarrollo de la teoría antropológica. Historia de las teorías de la cultura. Madrid, Siglo XXI, 1979, p. 71 
hasta dieciocho siglos más tarde. ${ }^{23}$

Según mis investigaciones, lo que podemos observar como proceso histórico es más bien cómo los europeos, en especial los españoles, aplicaron en el continente americano a su llegada diferente ideas e instituciones que acompañaban a esas ideas y que tenían un arraigo muy fuerte dentro de Europa desde mucho antes de que apareciera América en su radar. Así vemos que la denominación de "indios" no es una "invención racial". Es producto de la confusión geográfica de las nuevas tierras con la India. Con el tiempo, esta denominación adquiere rasgos y justificaciones que tienen que ver con la concepción del mundo europeo, que estaba en plena transición, desde el predominio de la visión teológica hacia la conformación científica. Transición que dura, al menos, trescientos años. De allí que los primeros debates fueran sobre la posesión de almas o que se viera a los "indios" como el "hombre natural". Fijémonos que ya Lucrecio, en el siglo I d.C, es decir catorce siglos antes de América, planteaba que:

Los primeros hombres eran como brutos, más toscos que los hombres modernos, con huesos más gruesos, con músculos más robustos, menos afectados por los rigores del clima. En un principio, los hombres vivían como bestias, sin arado y $\sin$ útiles de hierro con los que trabajar en los campos, plantar y cortar los árboles. Aquellos primeros hombres no comían más que lo que el sol y la lluvia les querían dar; no tenían ropas ni construían viviendas permanentes, sino que se refugiaban en cuevas y abrigos hechos con ramas. ${ }^{24}$

Esta es la visión que se desenvuelve en los primeros años de la conquista. Tampoco las instituciones que Quijano entiende como "raciales" son la consecuencia de la colonización de América. Son de hecho la aplicación de las relaciones sociales europeas de ese momento, en las cuales predominaba la sociedad dividida en castas. De esta forma se pueden comprender las diferenciaciones entre los españoles "puros" y los "no puros" (cristianos - no cristianos, europeos - no europeos), que en el ideal de la época, es decir en la episteme de la época, hacía referencia a los "cristianos viejos" en oposición a los conversos, devenida de las luchas religiosas que afectaban gran parte del mundo europeo de entonces. Por ese motivo, la importancia que muchos daban a la posibilidad de "conversión" de los indígenas.

Separemos las cosas. Bajo ningún punto de vista estoy negando que los europeos llegados a estas tierras hicieran desmanes muchas veces justificando los mismos con argumentos de la "superioridad" racial o cultural. Pero lo que estamos haciendo, como se propone Quijano, es construir una nueva episteme, la

23 Ibídem., p. 23.

24 Ibídem., p. 24. misma debe tener en cuenta la gran complejidad del proceso histórico y ser capaz de dotar de adecuado sustento empírico a sus afirmaciones teóricas. Varias corrientes que Quijano no duda en denominar como eurocentradas y coloniales ya han hecho simplificaciones que han costado mucho a las ciencias sociales, y han llevado a la toma de decisiones políticas erróneas por partir de una comprensión inexacta de la realidad, basada en simplificaciones. De hecho, es la crítica más fuerte que el mismo autor le hace al materialismo histórico, por caso.

Para criticar la "episteme eurocéntrica" es necesario conocerla a fondo, sin simplificaciones banales, ya que esto nos confunde más, nos coloniza más. Debemos ser más, no menos, meticulosos a la hora de plantear críticas y asumir la responsabilidad de "crear una nueva episteme", tal como lo pretende el autor. Porque de lo contrario, tales simplificaciones nos pueden jugar en contra. Si la idea de raza se comprende como Quijano la plantea, ¿no se podría sostener acaso que los incas eran racistas? ¿Y los aztecas? De igual manera, no debemos desconocer que dentro de la misma Europa siempre hubieron voces disonantes a estas conformaciones epistémicas que Quijano critica, y a las cuales no reconoce, como también siempre hubo voces $y$ acciones disidentes respecto a las atrocidades cometidas por quienes detentaban el poder, a lo largo de todo el proceso de mundialización que comenzó, éste sí, en el siglo XVI. Sólo para poner un ejemplo de lo que planteo veamos qué opinión tenía Helvetius (y Locke) de lo que comenzaba a tomar forma como el evolucionismo biologicista:

Locke y yo decimos: la desigualdad de los espíritus es el efecto de una causa conocida. Y esta causa está en las diferencias de educación [...] Todo, pues, en nosotros es adquisición. [...] Nuestro conocimiento, nuestros talentos, nuestros vicios y virtudes y nuestros prejuicios y caracteres [...] no son, en consecuencia, efecto de nuestros diversos temperamentos hereditarios, Nuestras pasiones mismas no dependen de ellos. [...] He probado que la compasión no es ni un sentido moral ni un sentimiento innato, sino el simple efecto del egoísmo, ¿Qué se sigue de esto? Que es un mismo amor, diversamente modificado según la diferente educación que recibimos y según las circunstancias y las situaciones en que la suerte nos ha colocado, el que nos hace humanos o insensibles..$^{25}$

Por último, para cerrar con el tema de la racialidad es imprescindible llamar la atención sobre otro de los puntos que me parecen de mayor trascendencia. La importancia de África en la constitución del racismo. No podemos desconocer que, en los siglos XVIII y XIX, es cuando se produce un incremento de la trata negrera, momento en el cual aparece fuertemente la idea de raza para justificar la misma, junto a la colonización del continente africano y sus poblaciones. Poner el énfasis de la idea de raza

25 Cit. en Ibídem., p. 34 
en América invisibiliza este proceso. No se trata de ver quién ha sufrido más, sino de lograr comprender los procesos históricos con todas sus complejidades y contradicciones. $Y$ no debemos perder de vista que las "teorías seudocientífcas de las razas biológicas [surgen para] demostrar la existencia de diferencias entre las razas desde el punto de vista físico y mental, con el fin de justificar el mercado de personas". ${ }^{26}$ No sólo América ha sido víctima de la opresión por parte de ciertas élites europeas a lo Largo de la historia, también lo han sido África, Asia, Oceanía y la misma Europa.

\section{La episteme eurocentrada}

A esta altura del análisis del pensamiento de Quijano era creciente en mí el cuestionamiento en lo referente a la propuesta que éste desarrolla. Dos de los grandes núcleos de la teoría no tenían suficiencia ni en los procesos históricos ni en la historia del pensamiento. En su afán de hacer una generalización que explicara las diferencias raciales, Quijano mezclaba muchas cosas, quizá demasiadas, sin una fundamentación que pudiera servir de base. De hecho, es muy difícil encontrar esas argumentaciones, ya que la mayoría de sus escritos son artículos relativamente cortos, de extensión inadecuada para un abordaje profundo de los complejos temas que trata. Por lo general, su estrategia argumentativa es hacer fuertes afirmaciones y luego citar un artículo en el cual ese tema supuestamente está desarrollado. Es cierto que en los artículos señalados se debaten esos temas. Pero, insisto, no con la profundidad que ameritan discusiones que pretenden romper con las lógicas de conformación de conocimiento y rediscutir la explicación de procesos históricos profundos y prolongados en el tiempo.

En la perspectiva de Quijano, todo surge en el siglo XV. La colonialidad, el nuevo patrón de poder, el capitalismo, la modernidad y la episteme eurocentrada. Uno de los principales problemas con este enfoque es que el mundo aparece como si no hubiera tenido historia antes del ingreso de América al imaginario europeo. Es, si se me permite la expresión, una forma distorsionada de eurocentrismo, porque lo trascendental sigue siendo el ingreso de América al mundo europeo. Sin embargo, esta forma de encarar el proceso histórico desconoce que si bien es innegable que la llegada de los europeos al continente, y todo lo que acontece después, modifica al mundo en variados sentidos, debemos tener presente que las instituciones y las relaciones no se "inventan" allí. Jamás Quijano hace referencia a los procesos anteriores a la llegada de los europeos a América. Una mente incauta puede quedar enceguecida con su planteamiento. Pero

26 Sandra Morales Fundora, El negro y su representación social (Aproximaciones a la estructura social cubana actual), La Habana, Editorial de Ciencias Sociales, 2001, p. 5. es un planteamiento fragmentario que simplifica terriblemente la historia. Historia que no empieza en 1492 y para lograr una comprensión de la importancia de los acontecimientos, debemos tener presente el complejo marco de relaciones mundiales que existía antes de la mundialización de las relaciones sociales. Mundialización que comienza en el siglo XV no por el ingreso de América al imaginario europeo, sino porque en ese momento una parte de Europa tuvo los avances tecnológicos y militares que le permitieron explorar lo mares como nunca antes ningún otro pueblo había podido hacerlo y llegar así tanto a América como a la parte sur de África y a islas antes inexploradas, ocuparlas y colonizar a sus poblaciones:

Que la expansión atlántica sólo podían protagonizarla los países marítimos del suroeste de Europa, es una evidencia avalada por la acumulación de conocimientos cosmográficos, el desarrollo de las artes cartográficas y la notable evolución de conocimientos técnicos en el arte de marear, entre los que el descubrimiento de la carabela representaría un avance sustancial en el dominio de la navegación a vela que llevaría a los nautas de su tiempo a abrir nuevas rutas oceánicas. ${ }^{27}$

Comprender esto nos ayuda a entender por qué las cosas sucedieron de una forma y no de otra. La historia no siguió un camino pre-escrito, como el presente no sigue un único destino posible. Esta concepción nos permite comprender la conformación de las relaciones sociales que se expresan en instituciones y en valores, sean morales o culturales. Quiero decir con esto que la investigación histórica busca las diferentes causas por las cuales los hechos acontecieron de una forma y no de otra. Sea que los historiadores adhieran a una teoría explicativa, que busquen una comprensión o solamente se queden en la descripción, mayoritariamente en la actualidad, y ya desde los años 80 del pasado siglo, se ha logrado quebrar la visión positivista. Aquella que, entre otras cosas, planteaba que la historia había sido de una manera y no podría haber sido de otra. En realidad, hace décadas que, cuando miramos al pasado, lo que pretendemos es entender los diferentes factores que actuaron para la conformación actual de las sociedades.

Esta complejidad que tiene el análisis histórico queda en manos de Quijano desecha porque su planteamiento queda entrampado en esa lógica de pensamiento positivista del siglo XIX, en la cual se pensaba que las cosas no podrían haber sido de otra forma. Más de una vez, sus argumentos van en este sentido. $Y$ sabemos por la experiencia histórica justamente que esta forma de encarar la reconstrucción de nuestro pasado es muy sesgada y nos lleva a errores de interpretación. Cuando uno analiza de forma sesgada el pasado, conforma muchas veces un análisis igual de sesgado

27 José Antonio Armillas, "Descubrimiento y contacto con otros mundos", en Alfredo Floristán (coord.), Historia moderna universal, Barcelona, Ariel, 2015, p. 29 
para el presente. Debemos buscar en el pasado los diferentes factores que actuaron para que los acontecimientos tomaran el rumbo que tomaron y no otro. A esto se refieren los epígrafes elegidos para este escrito. Si comprendemos esto, podremos tener una mirada más liberadora.

De acuerdo con esto, es importante resaltar que si bien Quijano intenta romper con la episteme moderna eurocentrada y pone a América como el centro en sus escritos, siempre hay mayor referencia a los procesos que acontecieron en Europa que a cómo se vivía y vivió la llegada de los europeos desde los diferentes pueblos que habitaban con anterioridad el continente. Parecería ser que las consecuencias del "actual patrón de poder", como denomina a las formas que han tomado las relaciones sociales desde el siglo XV, tienen que ver con el "poder" que tuvo Europa para imponerse cuando, en realidad, hubieron muchísimos factores que influyeron en el trascurso de los cinco siglos que el autor intenta analizar. Por caso, si no comprendemos los funcionamientos sociales que predominaban entre las sociedades que habitaban este continente, no podemos comprender por qué la llegada de cientos de hombres tuvo el poder de dominar a millones. Y se idealiza el pasado americano, como sociedades sin conflictos, con mejores ideales, que tenían mejores valores que los europeos. Pero éstos, al estar conformados con la "avaricia" de la dominación en base a su creencia de superioridad, lograron dominar el resto del mundo. Desconocer, por ejemplo, que en cuestiones tecnológicas los europeos tenían superioridad respecto a los pueblos americanos es necesario, ya que si sólo terminaron dominando por "su creencia", por su "episteme" en la superioridad, indicaría que los pueblos que habitaban el continente no tuvieron ninguna resistencia en aceptar esa inferioridad de la cual estaban convencidos los europeos.

La historia del continente americano es rica y compleja, incluso desde antes de la llegada de los europeos. Quijano, empero, así como excluye la historia de Europa antes del siglo XV, excluye la historia de los pueblos americanos antes de la llegada de los europeos. Lo mismo pasa con los pueblos africanos. Hay que conocer su historia para comprender por qué los europeos pudieron establecer el colonialismo en el siglo XIX. Decir que sólo fue por la superioridad tecnológica (cuestión que Quijano nunca analiza y es muy importante cuando esa tecnología se expresa en armas) o que fue porque los europeos ubicaron como raza inferior a los africanos, es simplificar el proceso y terminar cayendo en una forma más de lo que él pretende denominar como eurocentrismo. Debemos tener en cuenta que el racialismo fue una forma de justificar hechos que efectivamente surge después de la dominación, no antes. Sin duda, es una herramienta eficaz una vez que ya, con la violencia de las armas o con la imposición de sus valores, el europeo ha ingresado en otras sociedades. En este sentido, Quijano confunde constantemente la causa con el efecto.
Pero no me quiero ir de tema, la simplificación histórica del autor me apremia. Empero me quiero centrar en la cuestión de la episteme moderna eurocentrada. Una y otra vez, Quijano mantiene la idea de una episteme europea que tiene supuestos en común y que se empezaría a conformar en el siglo $\mathrm{XV}$ y se mantendría, reformulándose pero sin cambiar sus principales características, hasta la actualidad. Aquí hay que especificar las pretensiones de un escrito universitario, ya que Quijano no está escribiendo por fuera de los ámbitos académicos, ${ }^{28}$ sino justamente desde sus centros (digo centros y no periferias, ya que numerosos artículos suyos han sido publicados en Estados Unidos, Francia e Italia, es decir en los centros propiamente dichos de producción del conocimiento). Esto requiere que se identifiquen los parámetros a partir de los cuales se va a llevar adelante la discusión. Porque es sabido que no es lo mismo hacer ciencia social que filosofía, por caso.

En este aspecto Quijano es confuso porque en su afán de tener en cuenta cosmovisiones otras, habla constantemente de saberes. Pero saberes incluye una infinidad de temas muy problemáticos que no son en realidad problematizados. ${ }^{29}$ Es innegable que cada sociedad tiene su cosmovisión (incluso puede tener varias), sus conocimientos respecto a la medicina natural y a todo lo que la rodea, y que también tiene algún tipo de "explicación", si se quiere, del funcionamiento del mundo y de las relaciones sociales. Pero también es sabido que esas cosmovisiones no buscan la comprensión o explicación de la misma forma que lo busca el "saber" científico. Por mucho que respetemos a otras cosmovisiones, no podemos negar ni la especificidad ni los logros relativos que el pensamiento científico ha generado a la humanidad. Es a partir de esta forma de concebir el conocimiento que se encontraron las vacunas para muchas enfermedades que con anterioridad han hecho estragos en la historia de la humanidad, que se ha logrado explorar el universo y que se han desarrollado todo tipo de herramientas que facilitan la vida del ser humano. Esto no significa que otras formas de conocimiento no sean válidas o que sean inferiores. Simplemente significa que son distintas. La exactitud que otras formas de adquirir

28 Es diferente el caso, por ejemplo, del Subcomandante Marcos. Sus escritos, no tienen pretensiones académicas, sino que buscan visibilizar otras cosmovisiones y la forma en que los pueblos de la Selva Lacandona han vivido la historia. Sería erróneo entonces acusarlo de que no respeta las reglas del campo intelectual. El caso de Quijano, sin embargo, es diferente, porque él sí pretende discutir la ciencia y la filosofía, la construcción del conocimiento académico o intelectual. Pero no se ciñe a ninguna de las reglas que en él imperan en cuanto a la forma de construir conocimiento. En cambio, nunca cuestiona el funcionamiento del campo académico. Su vida intelectual transcurre en congresos realizados en los grandes centros de hegemonía del conocimiento y en la publicación de artículos en lugares "reconocidos" por otros intelectuales. Y su participación política, cuando la tuvo, estuvo centrada dentro del marxismo, del que después busca "desprenderse", pero no estuvo centrada en la lucha de los pueblos indígenas. Su cosmovisión siempre fue occidentalista, inclusive cuando intenta salirse de ella.

29 Hablo de problematizado en el sentido de buscar el porqué. La ciencia problematiza porque además de intentar responder al qué, al cuándo y al cómo, busca además responder al porqué. 
conocimiento han logrado respecto al movimiento del universo por ejemplo, aún sigue sorprendiendo a los científicos. Pero es innegable que la ciencia es la que ha permitido, por ejemplo, la revolución comunicacional a partir del envío de satélites a la atmósfera Que este pensamiento científico se haya desarrollado en Europa antes que en otros lugares, es algo a explicar, no algo a condenar. Otra cosa muy distinta es que discutamos el uso que se hace del conocimiento científico. La ciencia no es ni mala ni buena, lo malo o bueno son los usos (y abusos) que hacemos de ella.

Además, dentro de la categoría "saberes" no sólo nos encontramos con otras cosmovisiones, sino también con lo que podemos denominar "sentido común" u "opinión", como se ha identificado a este tipo de saber desde Platón a nuestros días. La doxa se diferencia de la episteme, o el saber más específico, porque este último busca una reflexión y conocimiento sistemático respecto de lo que quiere conocer. ${ }^{30}$ Han transcurrido dos milenios, desde la exposición del gran filósofo griego y ha habido varias complejizaciones respecto al conocimiento que podemos denominar episteme.

Asimismo, hay que identificar si se pretende un conocimiento científico o filosófico, ya que cada uno aborda problemáticas distintas, tiene formas de abordajes de esas problemáticas que son particulares y propone un vocabulario específico. Quijano no parece tener en cuenta estas diferencias y en sus escritos siempre aparece una mezcla de lo que es el saber filosófico y el saber científico. No sólo en tanto a sus propuestas, sino más bien en la discusión que plantea de ciertos pensadores. Para él, Descartes, Hegel, Marx, Locke, Newton, Spinoza, todos ellos, forman parte de la episteme eurocentrada moderna en el mismo nivel, cuando en realidad lo único que podemos decir que tienen en común, si analizamos sus campos de pensamiento y el desarrollo de sus propuestas, es que nacieron en Europa. Igualmente, no desconocemos que éste es un tema muy discutido, pero, a pesar de ello, podemos marcar algunas diferencias entre el saber científico y el filosófico. Insisto en ello porque muchas veces las afirmaciones que hace Quijano respecto a un proceso histórico, por ejemplo, no tienen sustento fáctico, sino más bien parecen sustentarse en supuestos filosóficos e incluso metafísicos. Más adelante retomaré esta cuestión con ejemplos concretos. Pero es necesario hacer primero algunas distinciones.

La ciencia es un saber que se basa en supuestos, no discute la existencia de lo que analiza. Por ejemplo, la física da por supuesto la existencia del movimiento, las ciencias sociales dan por supuesto la existencia de relaciones sociales que se transforman en el devenir de la historia y dan por supuesto la existencia de personas que interactúan de formas complejas al tiempo

30 Un interesante texto sobre la diferencia entre conocimiento científico sentido común puede hallarse en Ernest Nagel, "La ciencia y el sentido común", La estructura de la ciencia, Buenos Aires, Paidós, 1978. que buscan comprender o explicar estas complejas formas de relación. Puede no haber acuerdo en si esas relaciones las podemos denominar como "sociedad", "cultura" o "civilización", si conforman totalidades con las sumas de sus partes, si se pueden o no separar en partes, si esas relaciones las llevan a cabo "sujetos", "individuos" o "gentes". Pero no hay duda de que las relaciones existen y que forman ciertas pautas de comportamiento. La filosofía, en cambio, se pregunta por esos supuestos y es sobre ellos que va a ir desarrollando a lo largo del pensamiento filosófico diferentes respuestas a estos cuestionamientos. Se pregunta si realmente existen las relaciones, si existe la "realidad", si existe el devenir. Otra de las diferencias entre saber filosófico y saber científico es que el científico es un saber acumulativo mientras que el filosófico es un saber no acumulativo, esto ha llevado a que se puedan plantear concepciones filosóficas que tienen fundamentos completamente distintos, como el idealismo y el realismo, o el empirismo y el racionalismo. Por último, cabe mencionar que la ciencia es un saber que busca, y necesita, la comprobación empírica, o fáctica en el caso de la historia por ejemplo, y que el saber filosófico es un saber que puede desarrollarse prescindiendo totalmente de ello, ya que puede ser sólo desarrollo especulativo, y por ello mismo indemostrable. Es en este último punto en el que, entiendo, Quijano tiene mayor confusión.

Por otra parte, si nos planteamos dentro del conocimiento científico (lugar que ocupa la sociología, desde donde escribe Quijano), debemos además ser claros: ¿buscamos comprender, describir, explicar? No se trata de lo mismo. Nuevamente, cada elección intelectual tiene particularidades específicas. La sociología se posiciona dentro de las ciencias sociales que buscan una explicación del mundo, no sólo una mera descripción ni específicamente una humanística comprensión. Y por último, si no estamos de acuerdo con todo este complejo abanico intelectual que se ha ido desplegando, con incontables variables, a lo largo de dos mil años, deberíamos al menos desarrollar una argumentación sobre por qué ninguna de esas formas de acceso al conocimiento nos parecen adecuadas para lo que se quiere presentar, y dar a conocer la propuesta epistémica. Lamentablemente, a lo largo de los escritos de Quijano se confunde descripción con explicación, comprensión, fundamentos filosóficos y determinismos históricos. Vuelvo aquí a utilizar un ejemplo anteriormente mencionado. El inicio de "todo" en 1492. Esta afirmación parece más bien estar fundada en una concepción metafísica, como cuando Hegel habla del Espíritu Absoluto como la consecuencia del devenir histórico, pero aplicada al pasado, más que en hechos factuales, al menos en su forma argumentativa.

Retomo nuevamente uno de los puntos trabajados con anterioridad, la idea constante en Quijano respecto a que algunos acontecimientos históricos no podrían haber sido de otra forma. 
Un grave error, ya que ni en las ciencias sociales, ni mucho menos en la filosofía, tenemos leyes absolutas que nos permitan tales aseveraciones. Así, se confunde lo que se debe explicar, en este caso el porqué en Europa en un momento dado de la historia se conforma el capitalismo, con la idea de que una pretendida superioridad europea metafísica hizo que los procesos fueran de esa forma y no podría haber sido de otra.

Un ejemplo de esta forma de encarar lo histórico, es decir de entender que las cosas no podrían haber sido de otra manera, lo encontramos cuando Quijano habla de la constitución de la modernidad europea:

¿Cómo se podría imaginar, sin América, el advenimiento de la peculiar utopía europea de los siglos XVI y XVII en la cual ya podemos reconocer los primeros signos de una nueva racionalidad, con la instalación del futuro como reino de la esperanza y de la racionalización, en lugar de un omnipresente pasado [...]?.31

Aquí nuevamente cae en un error, ya que no tiene en cuenta el pasado del pensamiento europeo. Los ideales de sociedades que funcionen de una forma más justa que las que están viviendo quienes desarrollan sus pensamientos se pueden rastrear en la Grecia clásica. Justamente La república de Platón es una propuesta de cómo debería funcionar una sociedad regida por los valores del bien y de la justicia. Además de ello, uno de los mitos que más ha sido desarrollado en el imaginario de Occidente, el mito de la Atlántida, también puede leerse en este sentido.

Del mismo modo, la idea de que "sin el nuevo lugar del futuro en el imaginario de la humanidad, la mera idea de modernidad sería simplemente impensable ${ }^{132}$ es al menos muy discutible, ya que justamente la idea de modernidad históricamente ha denotado una ruptura con el pasado, con lo "antiguo", más que una visión utópica de futuro.

El término moderno ha realizado un largo camino. [...] La palabra latina modernus fue usada por primera vez en el siglo $\checkmark$ para distinguir el presente, ya oficialmente cristiano, del pasado romano pagano. Con diversos contenidos "moderno" expresó una y otra vez la connivencia con una época que se mira así misma en relación con el pasado, considerándose el resultado de una transición desde lo viejo hacia lo nuevo [...]. El modernismo romántico quiso oponerse a los viejos ideales de los clásicos; buscó una nueva era histórica y la encontró en la idealización de la edad media. ${ }^{33}$

31 A. Quijano, Modernidad, Identidad y Utopía en América Latina, Quito, Sociedad y política, 1988, p. 12.

32 A. Quijano, op. cit., p. 12.

33 Jürgen Habermas, "Modernidad: un proyecto incompleto" en Nicolás Casullo (comp.), El debate modernidad-posmodernidad, Buenos Aires, Retórica, 2004.

\section{La episteme moderna}

Como vimos en el apartado anterior, Quijano nunca termina de explicitar qué es lo que concibe como episteme o epistémico. Sin embargo, mayoritariamente, esta enunciación va de la mano con la idea de modernidad o moderno. Así habla de episteme moderna. Veamos qué es lo que Quijano entiende por moderno. Es importante rescatar que los primeros textos en los cuales se dedica a esta cuestión son de finales de la década del '80 del pasado siglo. Justamente una época en la que este tema está en auge, gracias al debate que se da entre "modernos" y "posmodernos", momento en el que esta segunda corriente filosófica comienza a tener una fuerte presencia en los ámbitos intelectuales.

En el pensamiento de Quijano, el concepto de modernidad es definido de forma bastante ambigua. En los escritos más recientes, el autor plantea que:

Desde el siglo XVII, [...] fue elaborado y formalizado un modo de producir conocimiento que daba cuenta de las necesidades cognitivas del capitalismo: la medición, la cuantificación, la externalización (objetivación) de lo cognoscible respecto del conocedor, para el control de las relaciones de las gentes con la naturaleza, y entre aquellas respecto de ésta, en especial de la propiedad de los recursos de producción. ${ }^{34}$

Pero, para el autor, no se puede comprender ese "paradigma moderno" sin tener en cuenta la racionalidad surgida del mismo. Aquí nos encontramos con que, si desde el vamos es difícil identificar qué es lo que el autor denomina como "modernidad", más aún lo es entender qué es lo que entiende por racionalidad. De hecho, Quijano parece mezclar dos concepciones. Por un lado, rastrea el surgimiento de la racionalidad/modernidad y pone como punto de partida ahistóricamente el desarrollo que hace Descartes en la filosofía. En el mismo escrito en el que introduce la idea de colonialidad, "Colonialidad y modernidad/racionalidad" -ya trabajado en un apartado anterior-, sintetiza una de sus concepciones de racionalidad. Citaré en extenso, pues me parece importante analizar el pasaje:

En primer término, en ese presupuesto, "sujeto" es una categoría referida al individuo aislado, porque se constituye en sí y ante sí mismo, en su discurso y en su capacidad de reflexión. El "cogito, ergo sum" cartesiano significa exactamente eso. En segundo termino, "objeto" es una categoría referida a una entidad no solamente diferente al "sujeto/individuo", sino externo a él por su naturaleza. Tercero, el "objeto" es también idéntico a sí mismo, pues es

34 A. Quijano, "Colonialidad del poder y clasificación social", op. cit., p. 286. 
constituido de "propiedades" que le otorgan esa identidad, lo "definen", esto es, lo deslindan y al mismo tiempo lo ubican respecto de los otros "objetos".

Lo que está en cuestión en ese paradigma, es, primero, el carácter individual e individualista del "sujeto", que como toda verdad a medias falsea el problema al negar la intersubjetividad y la totalidad social, como sedes de la producción de todo conocimiento. Segundo, la idea de "objeto" no es compatible con el conocimiento a que llega la investigación científica actual, según el cual las "propiedades" son modos y momentos de un dado campo de relaciones, y en consecuencia no hay mucho lugar para una idea de identidad, de originalidad ontológicamente irreductible, al margen de un campo de relaciones. Tercero, la exterioridad de las relaciones entre "sujeto" y "objeto", fundada en diferencias de naturaleza, es una exacerbación arbitraria de las diferencias, puesto que la investigación actual llega más bien al descubrimiento de que hay una estructura de comunicación más profunda en el universo. ${ }^{35}$

En primer lugar, es inadecuado el intento de sintetizar en tan pocas líneas el desarrollo filosófico de Descartes, como el de cualquier otro pensador que, por diferentes motivos, ha pasado a formar parte de la historia. En segundo lugar, la propuesta no está situada. Nuevamente, se desconoce el contexto en el cual Descartes está planteando esta problemática, como también con quiénes está discutiendo y cuáles son sus intenciones. $Y$ todo ello se mezcla con los usos que, en algunos casos, se han hecho de la teoría. Responsabilizar a Descartes de todas las implicancias que sin mayores argumentos le atribuye Quijano, puede seducir a quienes desconocen el campo específico del desarrollo filosófico, como me aconteció a mí misma en un momento. Pero nomás me introduje en los debates de la filosofía, lamentablemente observé que nuevamente sus postulados no tenían forma de ser aceptados. Lamentablemente, y creo que es una de las fortalezas que ha sostenido a las propuestas de Quijano, es tal el punto de simplificación que hace que desarmar ese entramado me llevaría a tener que hacer un comentario extenso del contexto y del desarrollo del pensamiento filosófico cartesiano, lo cual excede ampliamente el objetivo de este trabajo.

$Y$ es en este punto en el que quedamos entrampados. Recuerdo que, cuando sin tener el conocimiento sobre estos temas que tengo en la actualidad, discutía con personas que criticaban el planteamiento de Quijano, yo resolvía la discusión muy fácilmente. Convencida, como estaba, de que el autor sabía de lo que escribía, acusaba a mi interlocutor de que su falta de empatía y su incomprensión del planteamiento eran causados por su colonización epistémica. Después de varios años de seguir formándome, me encantaría seguir sosteniendo esa postura, pero si quiero ser honesta, no puedo. Es tan grave, tan -paradójicamente- compleja la simplificación que realiza Quijano que es difícil demostrar sus errores. Lamentablemente, es aquí donde utiliza lo que supuestamente critica, el privilegio epistémico. Al ser un intelectual reconocido por diferentes centros de poder, su palabra tiende a la sacralización. Ninguna persona dudaría de que sus afirmaciones están sostenidas por serios análisis de las cuestiones que se encarga de debatir, porque justamente pertenece a la élite intelectual. Una persona que no se dedica a la cuestión puede entender que su planteamiento es verdadero y poner a cualquiera que se atreva a criticarlo en el lugar de "epistémicamente colonizado", más si en esas críticas es necesario defender a los pensadores que él critica. Si defiendo a Descartes, me acusarán de estar colonizada. Pero quien quiera oír que oiga: Descartes es mucho más que lo que plantea Quijano, y sus críticas destrozan a un hombre de paja.

Retomemos lo que había planteado como una ambigüedad de Quijano a la hora de definir la modernidad/racionalidad eurocentrada. Vimos, por un lado, que constantemente hace enunciados situando su surgimiento en el siglo XV: "En 1492, con el nacimiento de América y de Europa, del capitalismo y de la modernidad"; 36 "América Latina, [...] es un sujeto fundamental de la historia de los últimos 500 años. Con la constitución de lo que hoy llamamos América, se constituye también el capitalismo mundial y comienza el período de la modernidad"; ${ }^{37}$ más aún: "Con la constitución de América (Latina), en el mismo momento y en el mismo movimiento histórico, el emergente poder capitalista se hace mundial, [...] y como ejes centrales de su nuevo patrón de dominación se establecen también la colonialidad y la modernidad". ${ }^{38}$ Pero vemos que, cuando busca definirla, la sitúa en el siglo XVII, como en la cita que está al principio de este apartado. Vemos entonces una incongruencia del recorte histórico, ya que entre uno y otro momento pasaron ni más ni menos que casi doscientos años.

Por otro lado, Quijano sitúa como uno de los puntos fundantes de ese pensamiento moderno/racional a la filosofía cartesiana. En otro de sus escritos en que se encarga del tema sostiene:

En el proceso de producción de la modernidad, la idea de racionalidad inherente a ella no significaba lo mismo, en cada uno de sus centros productores y difusores en Europa. De manera simplificada, en los límites de este trabajo, podría señalarse que en los países del norte o sajones, la idea predominante de racionalidad se vincula, desde la partida, fundamentalmente a lo que desde Horkheimer se conoce ahora como la razón instrumental. Es ante todo, una relación

36 A. Quijano, "América Latina en la economía mundial", op. cit., p. 2005.

37 A. Quijano, "El trabajo al final del siglo XX", Cuestiones y horizontes..., op. cit., p. 271.

38 A. Quijano, "Colonialidad del poder y clasificación social", op. cit., p. 286. 
entre fines y medios. Lo racional es lo útil. Y la utilidad adquiere su sentido desde la perspectiva dominante..$^{39}$

Puedo decir que donde más ha predominado la "racionalidad instrumental" a la que hace referencia Horkheimer es en el empirismo filosófico, uno de cuyos exponentes principales es Hume, quien hace su obra justamente discutiendo con el racionalismo filosófico que había presentado Descartes y que dará lugar al positivismo lógico del siglo XX.

Vemos aquí una mezcla de diferentes formas de pensamiento desarrollada en Europa y que, cuando uno se sumerge en ellas, cuesta mucho ver por qué el autor las presenta como si fueran de una misma raigambre o como si hubiesen dado un mismo resultado, más porque no desarrolla -siempre por falta de espacio- cómo va uniendo sus propuestas epistémicas. En el caso de la anterior cita, se fusionan fuertemente dos corrientes filosóficas antagónicas que se desarrollaron durante los primeros años de lo que el autor denomina modernidad.

Veamos otra de las generalizaciones que plantea Quijano cuando habla de un invento suyo, el "empirismo atomista". Lamentablemente, nunca explica a qué se refiere con estos conceptos que no tienen existencia como teorías o paradigmas más allá de su propia mente. Es necesario hacer un excesivamente breve recorrido, solamente enunciado, de los cambios en el pensamiento occidental para comprender la equivocación del planteamiento expuesto. Debemos tener en cuenta que es a partir de Kant -de quien Quijano no se ocupa- que se diferencia con mayor intensidad las formas de conocimiento que se van a ir desarrollando. De su planteamiento referente a cómo se conforma el conocimiento se desprende la versión más acabada del idealismo en Hegel y luego las críticas de Nietzsche, Heidegger y Foucault, por sólo nombrar algunos de los filósofos que seguirán debatiendo estos presupuestos. Asimismo, se sentarán las bases, a partir de los neokantianos y la Escuela de Viena, de lo que se conocerá como positivismo y que en las primeras décadas del siglo $\mathrm{XX}$ se denominará positivismo lógico. Por último, se desprenderá de todo este andamiaje el marxismo haciendo una fuerte crítica al idealismo hegeliano y presentando una forma histórica de analizar las relaciones sociales en tanto relaciones entre los seres humanos y la forma de materializar los valores que en ellos predominan en cada momento histórico particular. Como vemos, el escenario es muy complejo y no se puede reducir a "una episteme moderna eurocentrada".

Las corrientes aunadas bajo un mismo concepto -episteme moderna eurocentrada- poseen en realidad disímiles supuestos filosóficos, diferentes prescripciones metodológicas, distintas

39 A. Quijano, Modernidad, identidad y utopía en América Latina, op. cit., p. 57. bases teóricas, incompatibles posiciones políticas y muy amplias implicaciones ideológicas. ¿Qué hay de común en todas ellas? Poco y nada. Aunque claro, regularmente pensaron a partir del mundo que les resultaba más familiar, y por ello en innúmeras ocasiones tendieron a universalizar erradamente (considerando universal cosas que en realidad no lo eran), a particularizar sin mayor sustento (atribuyendo a Europa, por ejemplo, características que compartían con otras culturas o civilizaciones), a menospreciar o ignorar a "otros" culturales, etc. Mostrar estas falencias es acertado y necesario. Pero atribuirlas a un marco epistémico común es insostenible. Sería como decir que hay una episteme intelectual que ignora y menosprecia a las personas iletradas: aquellas que o bien no saben leer o escribir, o bien no se dedican a ello habitualmente. $Y$ que dado que la explotación, la opresión y la discriminación siempre han contado a los letrados entre los grupos favorecidos, habría que desprenderse de la episteme intelectual. Pero no tiene mucho sentido, ¿verdad?.

\section{En el aire}

He utilizado mi experiencia personal, porque me parece realmente ilustrativa. En su momento, me sedujeron los planteamientos decoloniales. Pero al comenzar a hacer un estudio metódico de sus propuestas, para gran decepción me encontré que todo se desvanecía en el aire. Lo que en su momento pareció un oasis no terminó siendo más que un espejismo.

Entiendo que las problemáticas que se intentan abordar desde el "pensamiento decolonial" deben plantearse con seriedad y tenerse en cuenta para mejorar día a día la comprensión sobre el funcionamiento de las relaciones sociales que predominan en nuestro mundo. Personalmente, esto me parece sustancial cuando aún no renuncio a la utopía de construir una sociedad cada más justa, cada vez más igualitaria, cada vez más democrática. En palabras del Subcomandante Marcos, un mundo en el que quepan muchos mundos.

He trazado las líneas centrales que fui desgranado a lo largo de mis investigaciones. Todo lo planteado y muchas cosas que no he podido desarrollar me han llevado al abandono de esta forma de presentar el conocimiento y me han acercado nuevamente al marxismo. En él he hallado, leído con la misma meticulosidad, mundos riquísimos de análisis de lo social más allá del marxismo vulgar (que por cierto existe y abunda). $Y$ en este punto no puedo olvidar las palabras de un gran pensador que sintetiza mi posición:

Sin un compromiso profundo con el marxismo [...] habríamos 
buscado un puerto de refugio en la vida interior o bien nos abríamos colocado al servicio de los amos. Pero, entre quienes nos salvamos de estos dos destinos, sólo unos pocos conservamos una pequeña bolsa en la que, antes de lanzarnos al mar, guardamos, para preservarlos, los frutos más saludables de la tradición intelectual europea, el valor de la investigación, el fermento de la duda, la disposición al diálogo, espíritu de crítica, moderación en el juicio, rigor filológico, sentido de la complejidad de las cosas. Muchos, demasiados, se privaron de este bagaje: lo abandonaron, por considerarlo un peso inútil, o bien jamás contaron con él, pues se lanzaron al agua antes de haberlo adquirido. No se los reprocho, pero prefiero otras compañías [destacado $A B$ ]. ${ }^{40}$

\section{Bibliografía}

Anderson, Perry, Campos de batalla, Barcelona, Anagrama 1988. Bayer, Osvaldo (coord.), Historia de la crueldad argentina. Julio A. Roca y el genocidio de los Pueblos Originarios, Buenos Aires, Red de Investigadores en Genocidio y Política Indígena en Argentina, 2010.

Armillas, José Antonio, "Descubrimiento y contacto con otros mundos", en Alfredo Floristán (coord.), Historia moderna universal, Barcelona, Ariel, 2015.

Carpio, Adolfo, Principios de Filosofía. Una introducción a su problemática, Buenos Aires, Paidós, 2015.

Goody, Jack, La domesticación del pensamiento salvaje, Madrid, Akal, 1977.

Habermas, Jürgen, «Modernidad: un proyecto incompleto», en Nicolás Casullo (comp.), El debate ModernidadPosmodernidad, Buenos Aires, Retórica, 2004.

Harris, Marvin, El desarrollo de la teoría antropológica. Historia de las teorías de la cultura, Madrid, Siglo XXI, 1979.

Mignolo, Walter, "El lado más oscuro del Renacimiento", en Universitas humanística n. ${ }^{\circ}$ 67, 2009, pp. 165-203.

Morales Fundora, Sandra, El negro y su representación social (Aproximaciones a la estructura social cubana actual), La Habana, Editorial de Ciencias Sociales, 2001.

Nagel, Ernest, La estructura de la ciencia, Buenos Aires, Paidós, 1978.

40 Perry Anderson, Campos de batalla, Barcelona, Anagrama, 1998.
Pereyra, Carlos, El sujeto de la historia, México, Editorial Patria, 1988.

Pescador, José, Principios de filosofía del lenguaje, Madrid, Alianza, 1989.

Quijano, Aníbal, Modernidad, identidad y utopía en América Latina, Lima, Sociedad y política Ediciones, 1988.

Quijano, Aníbal e Immanuel Wallerstein, "La americanidad como concepto, o América en el moderno sistema mundial", en Revista Internacional de Ciencias Sociales n. ${ }^{\circ}$ 134, diciembre de 1992 pp. 583-591.

- (selección y prólogo de Danilo Assis Clímaco), Cuestiones y horizontes. De la dependencia histórico-estructural a la colonialidad/descolonialidad del poder, Buenos Aires, Clacso, 2014.

- (selección de Walter Mignolo), Ensayos sobre la colonialidad del poder, Buenos Aires, Ediciones del Signo, 2019.

Wallerstein, Immanuel, Las incertidumbres del saber, Barcelona, Gedisa, 2005.

\section{Resumen}

Este trabajo analiza críticamente el derrotero intelectual de Aníbal Quijano, con especial atención a sus contribuciones a la llamada opción decolonial, perspectiva teórica de la que puede ser considerado uno de los fundadores. Se estudia especialmente su concepción de la colonialidad del poder y su perspectiva sobre la etnicidad.

Palabras clave: colonialidad, decolonial, etnicidad, crítica, saberes.

\section{Abstract}

This paper critically analyzes the intellectual path of Aníbal Quijano, with special attention to his contributions to the so-called decolonial option, a theoretical perspective of which he can be considered one of the founders. His conception of the coloniality of power and his perspective on ethnicity are especially studied.

Keywords: coloniality, decolonial, ethnicity, criticism, knowledge. 